\title{
Reactivity and Kinetic Analysis of Coal Chars Combustion under Oxy-fuel Conditions
}

\author{
Hua FEI ${ }^{1, a}$, Pei-Sheng $\mathrm{LI}^{2, \mathrm{~b},{ }^{*}}$, Yuan-Lin $\mathrm{LI}^{1, \mathrm{c}}$, Jian-Hong DENG ${ }^{1, \mathrm{~d}}$ \\ ${ }^{1}$ Laboratory of Architectural Environment and Energy Application Engineering, Jiangxi University of \\ Science and Technology, Ganzhou 341000, Jiangxi Province, China \\ ${ }^{2}$ Research institute of thermal energy and power engineering, Nanchang University, Nanchang \\ 330031, Jiangxi Province, China \\ afeihua0928@163.com, 'lps20150331@163.com, \\ cliyuanli20090606@163.com, ${ }^{\mathrm{d}}$ Jianhongdeng@163.com
}

${ }^{*}$ Corresponding author

Keywords: Kinetic Analysis, Coal Char, Oxy-fuel, Combustion.

\begin{abstract}
The Oxy-fuel combustion of Yunfu bituminous (YFB) chars was studied by isothermal thermogravimetric experiments at $1273 \mathrm{~K}-1573 \mathrm{~K}$. The surface area of coal chars prepared at different stages of Oxy-fuel combustion was determined by BET methods. The pyrolysis temperature leads to a slight increase in the average pore diameter and surface area, and the average pore diameter of YFB increases with increasing carbon conversion. Pore structure parameters were calculated by random pore model. Compared to the experimental data, it is found that the random pore model has good ability to depict the reactivity of coal chars Oxy-fuel combustion under high temperature, indicating the random pore model was used to depict the reactivity of coal char combustion in Oxy-fuel.
\end{abstract}

\section{Introduction}

The combustion of coal chars for energy production results in the generation of greenhouse gases, with $\mathrm{CO}_{2}$ as the major contributor, which are emitted to the atmosphere ${ }^{[1]}$. There is a general agreement on the need to reduce the emissions of $\mathrm{CO}_{2}$; although the ways approach the problems are rather different. Combustion of fossil fuels in an Oxy-fuel environment is one of several promising new technologies for having a significant impact on reducing greenhouse emissions ${ }^{[2,3]}$.

Non-catalytic gas-solid reaction, such as coal combustion as well as gasification, which is influenced by many factors (such as atmosphere, pyrolysis time, temperature), is a very complicated phenomenon, particularly to coal char ${ }^{[4,5]}$. It has an abundance of submicropores, of which the surface areas have been thought to be predominant in the char reactions ${ }^{[6-8]}$.

Coal characterization has been extensively studied over the years ${ }^{[9,10]}$. The combustion of a porous carbon particle is a kinetic process. Coal char properties not only directly have impact on combustion and/or gasification reactions, but also intensify the complexity of the reaction ${ }^{[5,6,8]}$. Moreover, some researchers have conducted researches to study the emission of NO in Oxy-fuel combustion, and the main factors influencing NO emission have also been carefully investigated ${ }^{[2,3]}$. This can be of importance in revealing in-depth reaction mechanism in Oxy-fuel combustion atmosphere.

In this work, the combustion of Yunfu bituminous chars in Oxy-fuel was studied by isothermal thermogravimetric experiments. The characteristics of coal chars combustion at different temperatures were examined in Oxy-fuel.

\section{Experimental Section}

Yunfu Bituminous (YFB) coal was used in the present study as the representatives of coal. Coal samples were first crushed and sieved. Fractions in the size range of $<0.175 \mathrm{~mm}$ was used in the experiments. Elemental analysis and proximate analysis were carried out in vario EL-2 and TGA2000 (Navas Instruments, Spain), respectively. Coal properties are shown in Table 1. 
Tab.1 Coal Sample Analysis

\begin{tabular}{|c|c|c|c|c|c|c|c|c|c|}
\hline \multirow{2}{*}{ Sample } & \multicolumn{4}{|c|}{$\begin{array}{l}\text { Proximate Analysis(wt } \% \text {, } \\
\text { air-dried) }\end{array}$} & \multicolumn{5}{|c|}{$\begin{array}{l}\text { Ultimate Analysis (wt\%, } \\
\text { air-dried) }\end{array}$} \\
\hline & $\begin{array}{c}\text { Moistur } \\
\mathrm{e}\end{array}$ & $\begin{array}{l}\text { Volatil } \\
\mathrm{e}\end{array}$ & Ash & $\begin{array}{c}\text { Fixed } \\
\text { Carbo } \\
n\end{array}$ & $\mathrm{C}$ & $\mathrm{H}$ & $\mathrm{N}$ & $S$ & $\mathrm{O}$ \\
\hline $\begin{array}{l}\text { Yunfu Bituminous } \\
\text { (YFB) }\end{array}$ & 10.65 & 25.91 & $\begin{array}{c}17.1 \\
0\end{array}$ & 46.34 & 58.03 & 3.97 & 1.00 & 1.26 & 7.99 \\
\hline
\end{tabular}

Pyrolysis and combustion in the TGA: The experiments were carried out on thermogravimetric balance (STA 409) of Germanic NETZSCH Corporation. Firstly, coal samples were heated at a heating rate of $30 \mathrm{k} / \mathrm{min}$ up to the final temperature range of $1273 \mathrm{~K}, 1373 \mathrm{~K}, 1473 \mathrm{~K}, 1573 \mathrm{~K}$ at $\mathrm{N}_{2}$ atmosphere, and then atmosphere was changed to the mixed gas of $\mathrm{O}_{2} / \mathrm{CO}_{2}$ with the ratio of 1:4 for 20 30 minutes with a flow rate of $100 \mathrm{ml} / \mathrm{min}$.

Chars preparing in a tubular furnace: The tube furnace was first heated up to the temperature range of $1273 \mathrm{~K}-1573 \mathrm{~K}$, and then pumped in the mixed gas of $\mathrm{O}_{2} / \mathrm{CO}_{2}$ with the ratio of $1: 4$ at a flow rate of $100 \mathrm{ml} / \mathrm{min}$, and finally moved coal chars into heating zone rapidly to stay at predetermined time.

BET surface area analysis: The BET surface area of different coal chars was measured with a Micromeritics ASAP2020 automated gas adsorption apparatus. The adsorption/desorption isotherms $\left(\mathrm{N}_{2},-196^{\circ} \mathrm{C}\right)$ were determined using the TriStar 3000 gas absorption analyzer from Micromeritics. To ensure the reproducibility and accuracy of analysis, repeated experiments were accomplished.

\section{Results and Discussion}

The influence of temperature: Carbon conversion can be calculated by following equation

$$
X=\frac{m_{0}-m}{m_{0}-m_{a s h}}
$$

In which $m, m_{0}$, and $m_{\text {ash }}$ are instantaneous mass of solid reactant, initial mass of solid reactant, mass of solid ash, respectively.

Fig.1 (a) shows variation of the conversion with time for YFB combustion under Oxy-fuel atmosphere. It can be seen that carbon conversion increases with temperature at the same reaction time. The carbon conversions of YFB are $100 \%$ for $1573 \mathrm{~K}$ and $30 \%$ for $1273 \mathrm{~K}$ in three minutes, respectively. The relationships of carbon conversion and reaction rate of YFB chars are shown in Fig.1 (b). It can be seen from the figure that the combustion rate of coal char increases with temperature at the same carbon conversion. The combustion rate shows a maximum in the initial stage at $1473 \mathrm{~K}$. At $1373 \mathrm{~K}$ and $1573 \mathrm{~K}$, the combustion rate also shows similar trend, reaching maxima at carbon conversion of $36 \%, 28 \%$, respectively. It is thought that the pyrolysis of coal char has a significant effect on the combustion process ${ }^{[11,12]}$. Higher temperature increases coal char combustion rate, which means that long pyrolysis time leads to a reduction of combustion reactivity ${ }^{[13]}$. 

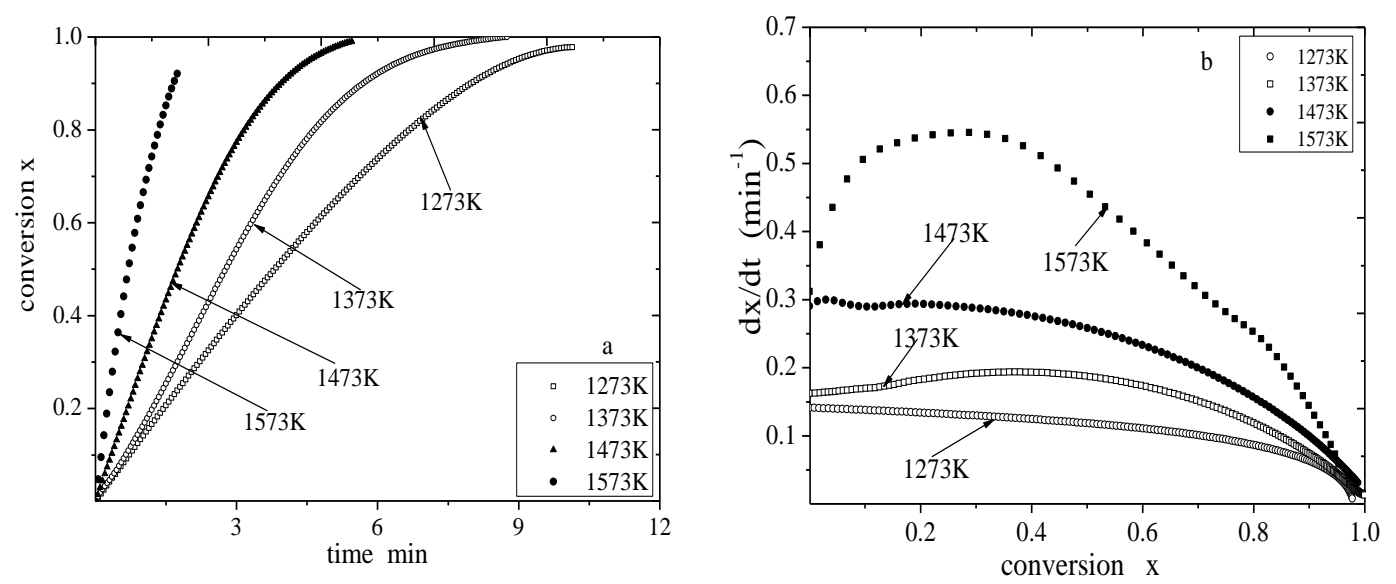

Fig. 1 The Effects of Temperature on Conversion and Combustion Rate $(d x / d t)$ of Coal Chars

Char properties: As can be seen from Fig.2, the changes of average pore diameter were small, which is consistent with Balci et al. ${ }^{[14]}$ studying results. The pyrolysis temperature leads to a slight increase in the average pore diameter and a reduction of surface area (see Fig.2 and Fig.4). Similar to the changes of YFB at $1573 \mathrm{~K}$, the average pore diameter of YFB increases with increasing carbon conversion at $1273 \mathrm{~K}$. This phenomenon is mainly related with the pore expansion and coalescence ${ }^{[15]}$. Fig. 3 shows variation of pore volume with carbon conversion during $\mathrm{O}_{2} / \mathrm{CO}_{2}$ combustion. As can be seen from Fig.3, pore volume shows a maximum at carbon conversion range of 0.2-0.4.

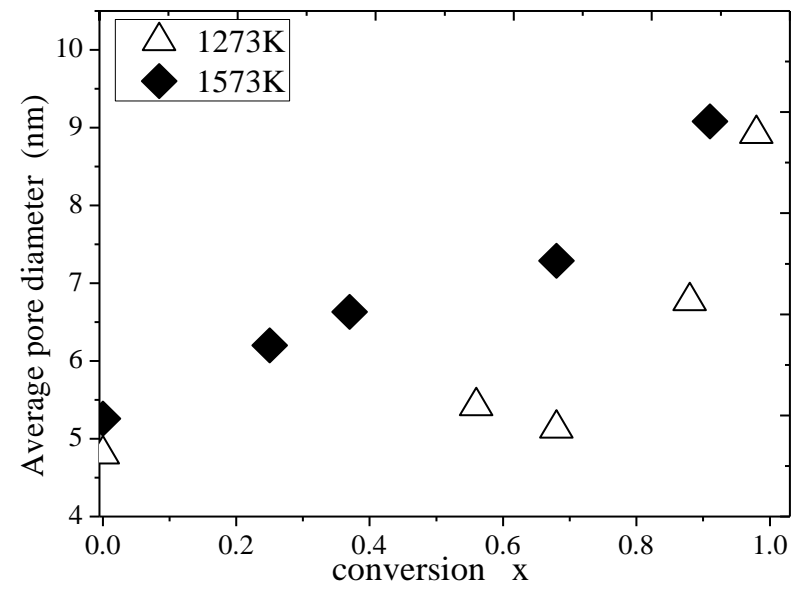

Fig.2 Relationship between Average Pore Diameter and Carbon Conversions

Surface area: To investigate relationship between char $\mathrm{O}_{2} / \mathrm{CO}_{2}$ combustion process and the variations of char structure, YFB chars were prepared at $1273 \mathrm{~K}$ and $1573 \mathrm{~K}$ in $\mathrm{O}_{2} / \mathrm{CO}_{2}$ using the tube furnace. The correlations between surface area of YFB and carbon conversion is shown in Fig.4. It can be seen that the surface area of YFB increases at $1273 \mathrm{~K}$ at the initial stage of reaction, this phenomenon is mainly caused by generation of a large number of new pores and micropore expansion $^{[15]}$, and then decreases when the carbon conversion is higher than above $50 \%$, which is mainly caused by pore collapse.

The random pore model (RPM) developed by Bhatia and Perlmutter ${ }^{[16]}$ as well as Gavalas ${ }^{[17]}$ is supported as being appropriate for application. This model accounting for the effects of pore growth and coalescence has often shown satisfactory agreement between theory and experiment. 


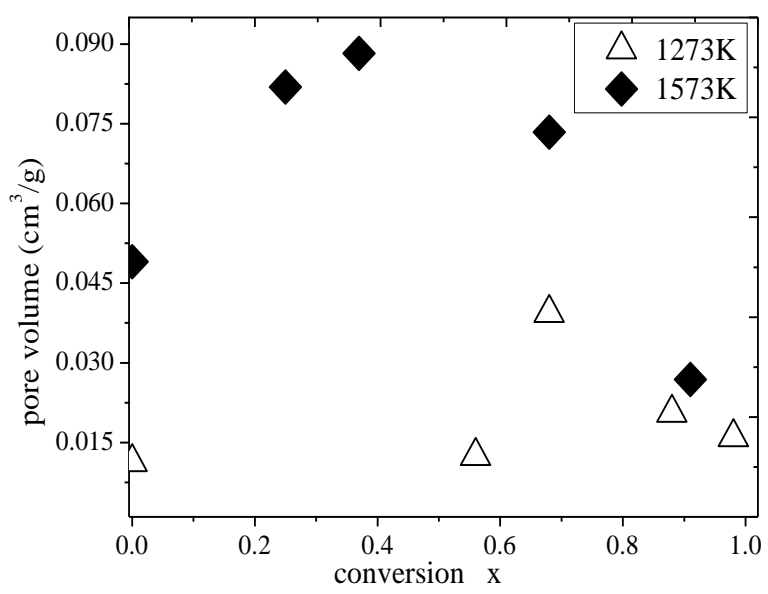

Fig.3 Relationship between Pore Volume and Carbon Conversions

The model equations ${ }^{[16]}$ derived for specific surface area with the conversion is denoted as

$$
S=S_{0}(1-X) \sqrt{1-\psi \ln (1-X)}
$$

Where $S_{0}$ is surface area of initial pore, $S$ is surface area of pore. $\psi$ is a structural parameter, which is also calculated by porosity per unit volume of reaction solid as follows ${ }^{[18]}$.

$$
\psi=1 / \ln \left(\frac{1}{1-\varepsilon_{0}}\right)
$$

In which $L_{0}$ is the total initial pore length per unit volume, $\varepsilon_{0}$ is the initial porosity.

The blank points in Fig. 4 are the simulated results calculated by random pore model. It can be seen from the figure that the model fits the experimental results well. Obviously, the random pore model can describe the variations of the surface area of coal char during $\mathrm{O}_{2} / \mathrm{CO}_{2}$ combustion process. But some minor deviations still exists when the RPM predicts the experimental data especially at the middle stage of reaction, which is related with the hypothesis of structure parameter in the random pore model ${ }^{[6,15]}$.

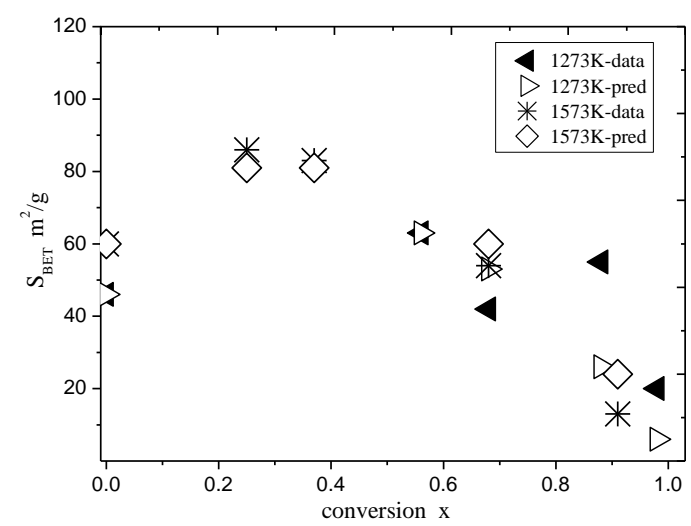

Fig.4 Surface Area and Simulation Results of Coal Chars at Different Conversion Ratios

\section{Conclusions}

1) Higher temperature increases coal char combustion rate, and the pyrolysis temperature leads to a slight increase in the average pore diameter and surface area.

2) The coal chars combustion in Oxy-fuel is investigated with the help of random pore model. Compared to the experimental data, surface areas predicted by the model are more satisfied to depict 
the experimental results.

3) The random pore model can be recommended as a convenient submodel for predicting the characteristic of coal chars combustion in Oxy-fuel.

\section{Acknowledgement}

This research was financially supported by the National Science Foundation(No. 51566012), the Natural Science Foundation of Jiangxi Province (No.20151BAB206048, 20142BAB203029, 20151BAB213025), the Project of Jiangxi Province Education Development Fund(No.GJJ150626, GJJ150616), and the Postdoctoral Science Foundation (No.2015M571991, 2015KY37). These supports are gratefully acknowledged.

\section{References}

[1] N. Kimura, K. Omata, T. Kiga, S. Takano, S. Shikisima, The characteristics of pulverized coal combustion in $\mathrm{O}_{2} / \mathrm{CO}_{2}$ mixtures for $\mathrm{CO}_{2}$ recover, Energy Conversion and Management 36(1995)805-808.

[2] J. Andersen, C. L. Rasmussen, T. Giselsson, P. Glarborg, Global Combustion Mechanisms for Use in CFD Modeling under Oxy-Fuel Conditions, Energy Fuels 23(2009) 1379-1389.

[3] J. Krzywanski, T. Czakiert, W. Muskala, R. Sekret, W. Nowak, Modeling of solid fuels combustion in oxygen-enriched atmosphere in circulating fluidized bed boiler, Fuel Processing Technology 10(2008) 1-6.

[4] B. Feng, S.K. Bhatia, Variation of the Pore Structure of Coal Chars during Gasification. Carbon 41(2003)507-523.

[5] T. Morimoto, T. Ochiai, K. Arakita, T. Kametani, H. Oda, Effects of Coal Grade and Gasification Condition on the Pore Characteristic Parameter of Coal Chars. Kagaku Kogaku Ronbunshu 31(2005)56-61.

[6] H. Fei, S. Hu, J. Xiang, L.S. Sun, P. Fu, G. Chen, Study on coal chars combustion under $\mathrm{O}_{2} / \mathrm{CO}_{2}$ atmosphere with fractal random pore model, Fuel 90(2011)441-448.

[7] S. J. Vyazovkin, Modification of the Integral Isoconversional Method to Account for Variation in the Activation Energy, Therm. Anal.Cal. 64(2001)829-835.

[8] H. Fei, L.S. Sun, S. Hu, J. Xiang, Y. Song, B. Wang, G. Chen, The combustion reactivity of coal chars in oxyfuel atmosphere: Comparison of different random pore models, Journal of Analytical and Applied Pyrolysis 91(2011)251-256.

[9] R. He, C.H. Chen, H.L. Fan, B. Zhang, X.C. Xu, Evolution of pore fractal dimensions for burning porous chars, Fuel 77(1998)1291-1295.

[10]S. Hu, M. Li, J. Xiang, L.S. Sun, P.S. Li, S. Su, X.X. Sun, Fractal characteristic of three Chinese coals, Fuel 83(2004)1307-1313.

[11]P.R. Bonelli, P.A. Della Rocca, E.G. Cerrella, A.L. Cukierman, Effect of pyrolysis temperature on composition, surface properties and thermal degradation rates of Brazil Nut shells, Bioresour. Technol. 76(2001)15-22.

[12]M. Guerrero, M.P. Ruiz, A. Millera, M.U. Alzueta, R. Bilbao, Characterization of Biomass Chars Formed under Different Devolatilization Conditions: Differences between Rice Husk and Eucalyptus, Energy Fuels 22(2008)1275-1284.

[13]T.F. Liu, Y.T. Fang, Y. Wang, An experimental investigation into the gasification reactivity of chars prepared at high temperatures, Fuel 87(2008)460-466.

[14]S. Balci, G. Dogu, T. Dogu, Structural Variations and a Deactivation Model for Gasification of 
Coal, Ind. Eng. Chem. Res. 26(1987)1454-1458.

[15]T. Morimoto, T. Ochiai, S. Wasaka, H. Oda, Modeling on Pore Variation of Coal Chars during $\mathrm{CO}_{2}$ Gasification Associated with Their Submicropores and Closed Pores, Energy Fuels 20(2006)353-358.

[16]S.K. Bhatia, D.D. Perlmutter, A Random Pore Model for Fluid-Solid Reactions: I. Isothermal, Kinetic Control, AIChE J. 26(1980)379-386.

[17] G.R. Gavalas, A Random Capillary Model with Application to Char Gasification at Chemically Controlled Rates, AIChE J. 26(1980)577-585.

[18] H.H. Rafsanjani, E. Jamshidi, M. Rostam-Abadi, A new mathematical solution for predicting char activation reactions, Carbon 40(2002)1167-1171. 